\title{
Comparison the New Kinetics Equation of Non- competitive Sorption Cd(II) and Zn(II) onto Green Sorbent Horse Dung Humic Acid (HD-HA)
}

\author{
${\text { Rahmat Basuki }{ }^{*} \text {, Ngatijo }{ }^{1} \text {, Sri Juari Santosa }{ }^{2} \text {, Bambang Rusdiarso² }}^{2}$ \\ ${ }^{1}$ Department of Chemistry, Faculty of Science and Technology, University of Jambi, \\ Jl. Jambi-Ma Bulian Km 15, Kampus Pinang Masak, Jambi 36136, Indonesia \\ ${ }^{2}$ Department of Chemistry, Universitas Gadjah Mada, Sekip Utara PO Box BLS 21, \\ Yogyakarta 55281, Indonesia
}

Received: $21^{\text {st }}$ November 2017; Revised: $28^{\text {th }}$ June 2018; Accepted: $3^{\text {rd }}$ July 2018; Available online: 14 ${ }^{\text {th }}$ November 2018; Published regularly: December 2018

\begin{abstract}
The new kinetics equation has been proposed and applied to the sorption of $\mathrm{Cd}(\mathrm{II})$ and $\mathrm{Zn}$ (II) onto green sorbent horse dung humic acid (HD-HA). This work aims to study the new kinetics equation and to compare its parameters with Lagergren and Ho kinetics equation in the same system. HD-HA was extracted and purified by Stevenson's methods and then characterized by detection of its functional group, UV-Vis spectra, and total acidity. The sorption study of this work was investigated by batch experiment in $\mathrm{pH}$ optimum 5. Langmuir's monolayer sorp-

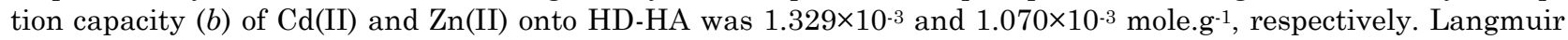
equilibrium constant $\left(K_{L}\right)$ of $\mathrm{Cd}(\mathrm{II})$ and $\mathrm{Zn}(\mathrm{II})$ sorption was 5,651 and 6,399 (mole/L) $)^{-1}$, respectively. The kinetics parameters were determined by Lagergren, Ho, and the new kinetics equation. The best linearity $\left(\mathrm{R}^{2}\right)$ and the most fitted sorbed metal ion in equilibrium $\left(x_{e}\right)$ with the experimental data was the Ho kinetics equation. However, the correct value of sorption rate constant $\left(k_{a}\right)$ was not really known, because the $k_{a}$ resulted from Ho and Lagergren kinetics equation can not be compared with another parameter and there is no scale to measure the correctness of this value of $k_{a}$. In this work, the correctness value of $k_{a}$ of the new kinetics equation can be measured by $k_{a} / k_{d}$ equal to $K$, and this $K$ should be equal to $K_{L}$. The values of $K$ of $\mathrm{Cd}(\mathrm{II})\left(3,452(\mathrm{~mole} / \mathrm{L})^{-1}\right)$ and and $\mathrm{Zn}(\mathrm{II})$ $\left(10,898(\mathrm{~mole} / \mathrm{L})^{-1}\right)$ were quite similar with $K_{L}$. Additionally, the value of intercept from linear regression of this new kinetics equation $(\mathrm{Cd}(\mathrm{II})=6.8517 ; \mathrm{Zn}(\mathrm{II})=6.0408)$ was highly similar with the manually calculation of $-\ln \left(x_{e} / a b\right)(\mathrm{Cd}(\mathrm{II})=7.0638 ; \mathrm{Zn}(\mathrm{II})=6.9838)$. These new kinetics equations also reveal that Lagergren sorption rate constant $\left(k_{\text {Lag }}\right)$ is the complex function of $\left.k_{a}\left(a b-x_{e}^{2}\right) / x_{e}\right)$. Copyright (C) 2018 BCREC Group. All rights reserved
\end{abstract}

Keywords: New Kinetics Equation; Non-competitive Sorption; Cd(II) and Zn(II); Horse Dung Humic Acid (HDHA); Lagergren sorption rate

How to Cite: Basuki, R., Ngatijo, Santosa, S.J., Rusdiarso, B. (2018). Comparison the New Kinetics Equation of Non-competitive Sorption Cd(II) and Zn(II) onto Green Sorbent Horse Dung Humic Acid (HD-HA). Bulletin of Chemical Reaction Engineering \& Catalysis, 13 (3): 475-488 (doi:10.9767/bcrec.13.3.1774.475-488)

Permalink/DOI: https://doi.org/10.9767/bcrec.13.3.1774.475-488

\section{Introduction}

In the history of kinetics sorption, predicting the sorption rate of sorbate onto sorbed for a given system is probably the most important

* Corresponding Author.

E-mail: rhmtbsq@gmail.com (R. Basuki)

Telp: +62-85743213964, Fax: +62-741-583111 factor in sorption system design, with sorbate residence time and the reactor dimensions controlled by the system's kinetics [1]. A number of sorption processes for pollutants have been studied in order to find a suitable explanation for the mechanisms and kinetics for sorting out environment solutions. In order to investigate the mechanisms of sorption, various kinetic 
models have been suggested. In recent years, adsorption mechanisms involving kineticsbased models have been reported. The earliest study of kinetic sorption has been developed since past decade by Lagergren (1898) [2]. Lagergren presented a first-order rate equation to describe the kinetics of liquid-solid phase adsorption of oxalic acid and malonic acid onto charcoal based on the sorption capacity [3]. It can be presented in Equation (1).

$$
\frac{d x}{d t}=k_{\text {lag }}\left(x_{e}-x\right)
$$

where $x_{e}$ and $x\left(\mathrm{mg} \cdot \mathrm{g}^{-1}\right)$ are the sorbate sorbed at equilibrium and at time $t$ ( $\mathrm{min}$ ), respectively, and $k_{\text {lag }}$ is the pseudo-first rate constant $\left(\mathrm{min}^{-1}\right)$. Eq. (1) was integrated with the boundary conditions at $t=0$ to $t=t$, and $x=0$ to $x=x$, to yield linear form in Equation (2).

$$
\ln \left(x_{e}-x\right)=\ln \left(x_{e}\right)-k_{\text {lag }} t
$$

Taking regression between $\ln \left(x_{e}-x\right)$ vs $t$ on this equation generates straight line, where slope is $-k_{\text {lag }}$ and intercept is $\ln \left(x_{e}\right)$. To distinguish the kinetic equations, based on sorption capacity from solution concentration, Lagergren's first order rate equation has been called pseudo-first order [3]. In recent years, it has been widely used to describe the adsorption of pollutants from wastewater in many different fields.

In 1995, Ho described the adsorption kinetics of divalent metal ions onto peat [4], in which the chemical bonding among divalent metal ions and polar functional groups on peat, such as: aldehydes, ketones, acids, and phenolics, are responsible for the cation-exchange capacity of the peat. The main assumptions were that the adsorption may be second-order, and the rate limiting step, may be chemical adsorption, involving valent forces through sharing or the exchange of electrons between the peat and divalent metal ions. The rate expression of pseudo-second order equation is:

$$
\frac{d q_{t}}{d t}=k_{H o}\left(q_{e}-q_{t}\right)^{2}
$$

where $q_{t}$ and $q_{t}\left(\mathrm{mg}^{\mathrm{g}} \mathrm{g}^{-1}\right)$ are the sorbate sorbed at equilibrium and at time $t$ ( $\mathrm{min}$ ), respectively. $k_{H o}\left(\mathrm{~g} \cdot \mathrm{mg}^{-1} \cdot \mathrm{min}^{-1}\right)$ is the pseudo-second rate constant. By integrating the equation with the boun-dary conditions at $t=t$ and $q_{e}=q_{t}$, it yields linear form as in Equation (4).

$$
\frac{t}{q_{t}}=\frac{1}{k_{H o} q_{e}^{2}}+\frac{1}{q_{e}} t
$$

Regression between $t / q_{t}$ vs $t$ on this equation generates straight line, where $q_{e}$ obtained from slope and $k_{H o}$ obtained from intercept.

Before the Ho kinetics equation, the other kinetics equations were proposed by Elovich [56], Ritchie [7], Sobkowsk and Czerwinski [8], and Blanchard et al. [9] equations. Elovich's equation was based on the adsorption capacity. This work was established though the work of Zeldowitsch by studying sorption of carbon monoxide on manganese dioxide. He found that sorbed gas was decreased exponentially with an increase in the amount of sorbed gas. It has commonly been called the Elovich equation in the following years. In 1977, Ritchie reported a model for the adsorption of gaseous systems. Assumptions were made as follows: $\theta$ is the fraction of surface sites which are occupied by an adsorbed gas, $n$ the number of surface sites occupied by each molecule of the adsorbed gas, and $a$ is the rate constant. In earlier years, Sobkowsk and Czerwinski presented a rate equation for the reaction of carbon dioxide adsorption onto a platinum electrode. They concluded that the first-order is only for low surface concentrations of a solid. In 1984, Blanchard et al. presented the overall exchange reaction of $\mathrm{NH}_{4}{ }^{+}$ions fixed in zeolite by divalent metallic ions. In recent years, the Blanchard second-order expression has been used to describe the kinetics of exchange processes between sodium ions from zeolite $\mathrm{A}$ and cadmium, copper, and nickel ions from solutions [10]. The equation and the origin rate can be seen in Table 1.

In past two decade, the Lagergren and Ho kinetics equation dominate the sorption kinetics study in publication. These two kinetics sorption equation is the most used to describe kinetics and mechanism of sorption in any systems [1,11-12]. In many cases, there was weakness of using Lagergren and Ho kinetics equation because the parameters value of these kinetic equations seems to be independent and have not a clear explanation because it can not be compared with another parameter and there is no scale to measure the correctness of this parameters value. In other words, it can be stated that the kinetic parameter is unknown whether it is really correct or not. In Lagergren equation, the intercept value $\left(\ln x_{e}\right)$ from regression of plot $\ln \left(x_{e^{-}} x\right)$ vs. $x$ is never be same with $\ln x_{e}$ from manual calculation of experimental data [13]. The value of rate constant $(k)$ was also changed with changing the initial concentration of sorbate [14]. Additionally, these both kinetics equation was not determined de- 
sorption rate constant $\left(k_{d}\right)$, where it was important in equilibrium system. This research proposed the new kinetics equation to give another view of kinetics sorption to overcome that weakness. The parameters obtained from this new kinetics equation can be compared with Langmuir data to confirm whether the parameters were really correct or not.

The new kinetics equation developed based on an approach that sorption is a dynamic equilibrium process and during mathematical derivation the availability of binding sites of sorbent of Langmuir model. The applicability of this new kinetic equation is then tested for the sorption of $\mathrm{Cd}(\mathrm{II})$ and $\mathrm{Zn}$ (II) on humic acid (HD -HA). These metal ion, Cd(II) and $\mathrm{Zn}$ (II) known as their distribution in soil and water has been to be strongly associated with the presence of humic substance [15]. HA was also reported to have widely used to reduce or eliminate metals in surface water [16-20]. HA generally extracted from peat soil as source. The usage of peat soil as source of HA has negative effect that is release stored carbon storage contributed to increasing the greenhouse effect [21]. Additionally, it can not be renewed immediately. To greening the source of HA, it can be used horse dung that it has high existence because it has a denser and rough texture, so it is rarely used for biogas and organic fertilizer [22]. The evaluation is carried out for the comparison the value of $k_{\mathrm{a}}$ of the sorption of $\mathrm{Cd}$ (II) and $\mathrm{Zn}$ (II) on
HD-HA by Lagergren, Ho, and this new kinetics equation. The sorption kinetic model was also evaluated for intercept of Lagergren kinetics equation $\left(\ln q_{e}\right)$ often found not equal between $\ln q_{e}$ from experiment [13] and the value of $k_{a} / k_{d}=K$ often was not same with Langmuir equilibrium constant $\left(K_{L}\right)$. Furthermore, study of the new kinetics equation was also critically discussed in this paper.

\section{Materials and Methods}

\subsection{Materials}

All reagent used in this work are analytical grade, i.e. sodium hydroxide, hydrochloric acid, fluoride acid, silver nitrate, barium hydroxide, calcium acetate monohydrate, cadmium(II) acetate dihydrate, and zinc acetate dihydrate supplied by Merck Co. Inc. (Germany) and used without further purification. HD-HA was extracted from dry horse dung powder from Bantul, Yogyakarta. As standard of humic acid, PS-HA was extracted from peat soil from Musi Banyuasin, South Sumatra. Extraction and purification was performed according to the procedure of IHSS under atmospheric air [23].

\subsection{Instrumentations}

These work used Hanna Instrument Portable $\mathrm{pH}$ Meter, magnetic stirrer, glass ware, and

Table 1. The summary of historical kinetics equations

\begin{tabular}{|c|c|c|c|c|}
\hline Author(s) & Ref. & Origin Rate & Linear form & Plot \\
\hline Lagergren & {$[2,3]$} & $\frac{d x}{d t}=k_{\text {lag }}\left(x_{e}-x\right)$ & $\ln \left(x_{e}-x\right)=\ln \left(x_{e}\right)-k_{\text {lag }} t$ & $\ln \left(x_{e}-x\right)$ vs. $t$ \\
\hline Elovich & {$[5,6]$} & $\frac{d q}{d t}=a e^{-\alpha q}$ & $q=\left(\frac{2.3}{\alpha}\right) \log \left(t+t_{0}\right)-\left(\frac{2.3}{\alpha}\right) \log t_{0}$ & $q$ vs. $\log \left(t+t_{0}\right)$ \\
\hline & & & With $t_{o}=1 / a a$ & \\
\hline $\begin{array}{l}\text { Sobkowsk and } \\
\text { Czerwinski }\end{array}$ & [8] & $\frac{d \theta}{d t}=k(1-\theta)^{n}$ & $\frac{\theta}{1-\theta}=k_{S C} t$ & $\theta /(1-\theta)$ vs. $t$ \\
\hline Ritchie & [7] & $\frac{d \theta}{d t}=a(1-\theta)^{n}$ & $\frac{q_{\infty}}{q_{\infty}-q}=\alpha t+1$ & $q_{\infty} /\left(q_{\infty}-q\right)$ vs. $t$ \\
\hline Blanchard et al. & [9] & $-\frac{d n}{d t}=K\left(n_{0}-n\right)^{2}$ & $\frac{1}{n_{0}-n}-\alpha=K t$ & $1 / n_{0^{-}} n$ vs. $t$ \\
\hline Ho & {$[1,4]$} & $\frac{d q_{t}}{d t}=k_{H o}\left(q_{e}-q_{t}\right)^{2}$ & $\frac{t}{q_{t}}=\frac{1}{k_{H o} q_{e}^{2}}+\frac{1}{q_{e}} t$ & $t / q_{t}$ vs. $t$ \\
\hline
\end{tabular}


Jena ContrAA 300 Atomic Absorption Spectroscopy (AAS) to analyze total metal ions in sample. The characterizations of horse dung humic acid (HD-HA) and peat soil humic acid (PS-HA) were performed by Shimadzu FTIR Prestige 21 and UV-visible spectrophotometer (GBC Cintra 2020).

\subsection{Extraction and Purification of HD-HA}

The sorbent (HD-HA) and the standard (PSHA) was extracted and purified by IHSS procedure [23] under atmospheric air. About $1 \mathrm{~kg}$ of sample (dry horse dung powder) was extracted based on acidity using $10 \mathrm{~L} \mathrm{NaOH} 0.1 \mathrm{M}$, stirred for 24 hours, and the filtrate was taken by centrifugation at $3000 \mathrm{rpm}$. Filtrate was then added by $0.1 \mathrm{M} \mathrm{HCl}$ to reach $\mathrm{pH} 1$, saved for 12 hours until two layers formed: humic acid (solid bottom layer). The crude HD-HA was separated by centrifugation at $5000 \mathrm{rpm}$ for 15 minutes and dried at $60{ }^{\circ} \mathrm{C}$. the same step conducted to extract PS-HA from dry peat soil powder. Crude HD-HA (and PS-HA) was purified by $\mathrm{HCl} / \mathrm{HF}$ methods. About $50 \mathrm{~g}$ of crude sorbent was added into $0.1 \mathrm{M} \mathrm{HCl} / 0.3 \mathrm{M}$ HF (1:1), stirred for 24, and the solid was taken by centrifuged at $5000 \mathrm{rpm}$. The $\mathrm{Cl}$ - residues in the sample were removed by washing with distillate water and then the sample tested by silver nitrate to detect $\mathrm{Cl}$ - residues. Purified sample, which was free of $\mathrm{Cl}$ - ion, was then dried at $60{ }^{\circ} \mathrm{C}$.

\subsection{Characterization of HD-HA}

Functional groups were determined by FTIR performed by mixing the well ground of sample with spectroscopic grade pellet $\mathrm{KBr}$ and pressed into a disk. The spectrum of absorption band was analyzed in wavenumber ranges of 400 to $4000 \mathrm{~cm}^{-1}$. Humification characterised by UV-Vis was performed by dissolving $10 \mathrm{mg}$ of sample in $\mathrm{pH} 11$ of $100 \mathrm{~mL}$ distilled water. Well mixed sample was inserted into a cuvet and analyzed at UV-vision region. Ash level analysis indicates the mineral content in sample. Ash level was determined by inserting 50 $\mathrm{mg}$ of sample into a crucible porcelain furnace at $750{ }^{\circ} \mathrm{C}$ for 4 hours. Each sample was repeated triplet and noted the changed of weight before and after furnace. Total of acidity was determined by Baryta indirect potentiometric titration method [23].

\subsection{Effect of Medium Acidity}

At first, a series of $50 \mathrm{~mL}$ of $\mathrm{Cd}(\mathrm{II})$ was prepared and their acidity was adjusted to 2.0, 3.0,
4.0, 5.0 , and 6.0 by adding $\mathrm{HCl}$ solution. Into every $\mathrm{Cd}$ (II) solution, $10 \mathrm{mg}$ of HD-HA was poured and then stirred for $2 \mathrm{~h}$. After filtering through 100 mesh membrane filter, the concentration of $\mathrm{Cd}(\mathrm{II})$ in supernatant was analyzed by using AAS. Sample and blank solutions were analyzed under same conditions. The amount of sorbed Cd(II) was considered to be the difference between the initial and the remaining amount in the reacting solution each time a sample was analyzed. The same procedure was conducted to $\mathrm{pH}$ optimum $\mathrm{Zn}$ (II).

\subsection{Sorption Isotherm}

The sorption isotherm experiments were carried out using a batch type reactor using 50 $\mathrm{mL}$ of Erlenmeyer in a water bath at $25 \pm 0.01$ ${ }^{\circ} \mathrm{C}$. As much as $10 \mathrm{mg}$ of sorbents was interact with and stirred in $50 \mathrm{ml}$ of solutions containing the various concentrations of $5,10,20,30$, $40,50,100,200$, and $400 \mathrm{mg} / \mathrm{L}$ of $\mathrm{Cd}(\mathrm{II})$ at $\mathrm{pH}$ 5.0 for $2 \mathrm{~h}$ and then aged for $24 \mathrm{~h}$. After separating the supernatants, the concentration $\mathrm{Cd}(\mathrm{II})$ in the supernatant was determined by AAS. Under the same condition with the sample solution, the blank solution was also analyzed. The same procedure was performed to the $\mathrm{Zn}(\mathrm{II})$ sample. The data obtained was then analyzed by Freundlich and Langmuir isotherm models.

\subsection{Sorption Kinetics}

The kinetics experiments also were carried out using a batch type reactor using $50 \mathrm{~mL}$ Erlenmeyer in a water bath at $25 \pm 0.01{ }^{\circ} \mathrm{C}$. The volume of sorption medium was $50 \mathrm{~mL}$, the initial metal ion concentration was $50 \mathrm{mg} / \mathrm{L}$, the acidity was adjusted at $\mathrm{pH}$ optimum; and to each solutions, $10 \mathrm{mg}$ of sorbent was added and then stirred continuously at $10,15,20,25,30$, $35,40,45,60,90$, and 120 minutes. The sample was immediately filtered through 100 mesh filter and the concentration of $\mathrm{Cd}$ (II) in the supernatant was analyzed by using AAS method. Sample and blank solutions were analyzed under the same conditions. The amount of sorbed $\mathrm{Cd}(\mathrm{II})$ was considered to be difference between the initial and the remaining amount in the reacting solution each time a sample was analyzed. The same procedure was performed to $\mathrm{Zn}$ (II) and data obtained was then analyzed by three different sorption kinetics models, i.e. new kinetics equation, Lagergren equation, and Ho equation. 


\section{Results and Discussion}

\subsection{Characterization of HD-HA}

The dark brown powder of sorbent (HD-HA) has the texture and appearance highly similar to peat soil humic acid (PS-HA). Characterization by UV-Vis spectrophotometer of $\mathrm{HA}$ is smoothly decreased and there are no maximum or minimum clear peak with increasing wavelength (Figure 1). The high absorbance emerges in the UV region and then decrease smoothly to visible region.

The smooth patterns from this study were similar to Stevenson's [23] and Agarwal's et al. [24] study. Characteristic of amount aromatic compounds $(\mathrm{C}=\mathrm{C}, \mathrm{C}=\mathrm{O}$, and $\mathrm{C}=\mathrm{N})$ and degree of humification were indicated in range of 250 $300 \mathrm{~nm}$. High absorbance of UV spectra of humic substance was commonly used to predict several molecular properties of humic substance. Prominent region should be spot approximately at $280 \mathrm{~nm}\left(\mathrm{~A}_{2}\right), 400-500 \mathrm{~nm}\left(\mathrm{~A}_{4}\right)$, and around $600 \mathrm{~nm}\left(\mathrm{~A}_{6}\right)$. The combination ratios of this absorbance indicates specific character of humic substances. $A_{2 / 4}$ indicates the portion of lignin and other materials at the beginning of the humification process [25]), while $\mathrm{A}_{2 / 6}$ indicates the portion between humificated and nonhumificated material. $\mathrm{A}_{4 / 6}$ indicates degree of condensation and polymerization of aromatic compounds (can be used to predict humification index) (Table 1). This combination ratio of UV-Vis spectra of HD-HA and PS-HA can be used to predict the humification index (maturity) that any correlation to content of acidity and sorption capacity. The lower value of $\mathrm{A}_{2 / 6}$ and $\mathrm{A}_{4 / 6}$ represents a higher degree of aromatic and maturity of organic material. The

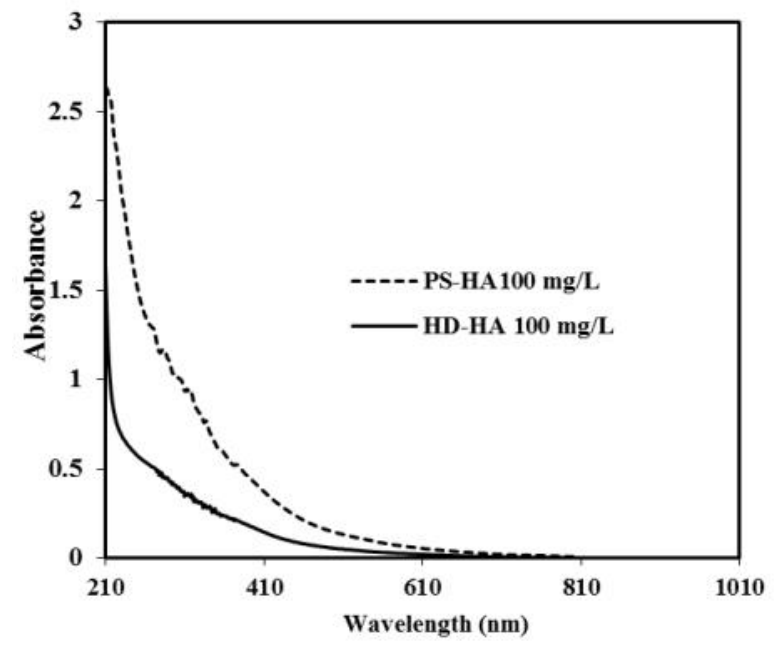

ratio $\mathrm{A}_{4 / 6}$ for $\mathrm{HA}$ should be lower than 5 , while FA is ranged 6 to 8.5 [23]. $\mathrm{A}_{4 / 6}$ ratio of PS-HA was higher than 5 (6.25) indicating the peat soil from Musi Banyuasin still young and humification still occur. The $\mathrm{A}_{4 / 6}$ ratio of HD-HA was also higher than standard and PS-HA. It is indicated that horse dung used in this work has not been humificated well.

Success purification makes clear the clay minerals, silicates, and disturbing metal impurities from sorbent [23], which is cover the surface of HD-HA. This impurities interact with active site of HD-HA, - $\mathrm{COOH}$ and phenolic $\mathrm{OH}$ which affected the total acidity and the $-\mathrm{COOH}$ and phenolic $-\mathrm{O}$ content. The lower ash level indicates that material have low of impurities. The yield of ash level of sorbent before purification were above $5 \%(\mathrm{w} / \mathrm{w})$, however after purification process, the results of ash level of PS-HA and HD-HA decrease below $5 \%$ i.e. 0.99 and $1.20(\% \mathrm{w} / \mathrm{w})$, respectively. Total acidity of HD-HA was also increased after purification process, but it is still below the total acidity of PS-HA and reference HA [23]. The lower total acidity agrees with fact that horse dung material used in this study is taken from open area and only about 3 month ages (Table 2 ). This result indicates the successfulness of purification process.

Comparison the FT-IR spectra of crude HDHA, purified HD-HA, crude PS-HA and purified PS-HA showed that both of HD-HA and PS-HA have high similarities in particular wave number absorption band of the functional group (Figure 1). There are five characteristic band of HA according to HA reference [23], i.e. $3300-3600 \mathrm{~cm}^{-1}$ indicates $\mathrm{O}-\mathrm{H}$ bond with hydrogen bond occurs inter molecule of active site

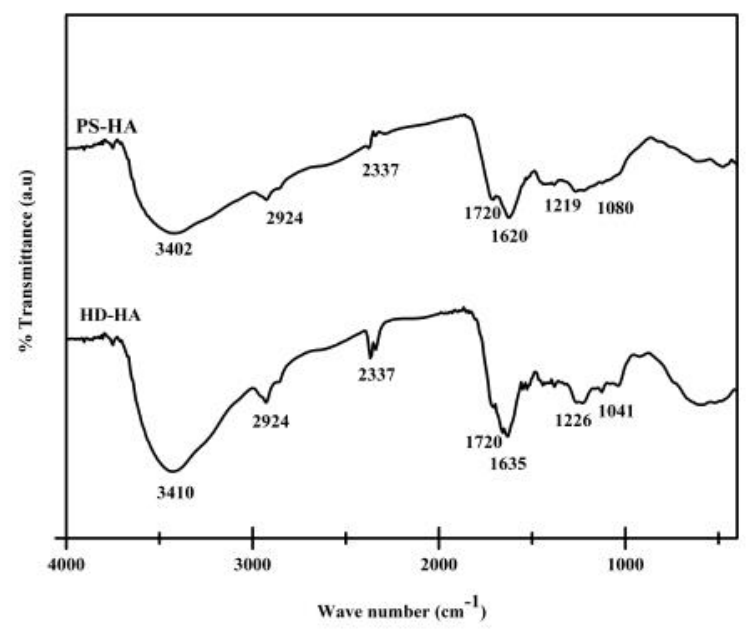

Figure 1. The characteristic pattern of UV-Vis absorbance (left) and FT-IR spectra of HD-HA and PSHA (right) 
HA that makes the band wider, about 2900 $\mathrm{cm}^{-1}$ indicates $\mathrm{C}-\mathrm{H}$ aliphatic stretching, about $1720 \mathrm{~cm}^{-1}$ indicates carbonyl group of $-\mathrm{COOH}$, about $1600 \mathrm{~cm}^{-1}$ indicates phi of aromatic alkene and aromatic rings of quinones which form hydrogen bond with $-\mathrm{OH}$ group, and about $1200 \mathrm{~cm}^{-1}$ indicates stretching of $\mathrm{C}-\mathrm{O}$ from $-\mathrm{COOH}$ group. Additional sharp peak commonly emerged at $2330 \mathrm{~cm}^{-1}$ which is not come from $\mathrm{HA}$, but come from $\mathrm{C}=\mathrm{O}$ stretching of carbon dioxide trapped in $\mathrm{KBr}$ pellet. Similar band as a characteristic of HA was also reported by Barot and Bagla in study of extraction HA from dry cow dung powder $[26,28]$.

\subsection{Effect of Medium Acidity}

Acidity is a function of amount $\mathrm{H}^{+}$in solution medium. It has high effect on the form of chemical substance or metal substance in aqueous medium [27]. Lower $\mathrm{pH}$ (high acidity) affects in decreasing the metal ions that attached in active site of sorbent as a result of competition between $\mathrm{H}^{+}$which the consequences is high concentration of unsorbed metal ions in solution. The result off this work indicates that the concentration of both sorbed $\mathrm{Cd}(\mathrm{II})$ and $\mathrm{Zn}$ (II) tend to increases with the decreasing of medium acidity (Figure 2). At higher $\mathrm{pH}$ medium, amount of hydronium $\left(\mathrm{H}^{+}\right)$ion was protonated and led to strong interaction among hydrogen and functional group of intermolecular HD-HA. In other word, the active site of HD$\mathrm{HA}$ was detected in $-\mathrm{COOH}$ or $-\mathrm{OH}$ form which cause the surface has positively charged and leads to repulsion between metal ions and functional group of HD-HA. Caused by this repulsion, the metal ions ( $\mathrm{Cd}$ and $\mathrm{Zn}$ ) which sorbed in HD-HA was very low. This condition makes attached metal ions on sorbent very low. There is no significant differences between sorbed $\mathrm{Cd}(\mathrm{II})$ and $\mathrm{Zn}(\mathrm{II})$, although the $\mathrm{Zn}$ (II) seems little higher sorbed than the Cd(II). This result can be compared to previous study that the $\mathrm{Zn}$ (II) was sorbed higher than $\mathrm{Cd}(\mathrm{II})$. When the $\mathrm{pH}$ of medium acidity higher than 2, HDHA's active site, $-\mathrm{COOH}$ and phenolic $-\mathrm{OH}$ start to be deprotonated that led to weakening in hydrogen bonds and the surface cover with negative charge. As a result, metal ion, $\mathrm{Cd}(\mathrm{II})$, and $\mathrm{Zn}(\mathrm{II})$ are easier to interact with active site of HD-HA and makes metal ion highly sorbed

Table 2. The absorbance ratio of UV-Vis spectra, ash level, and total acidity of HD-HA compared to PS-HA and Humic Acid reference

\begin{tabular}{|c|c|c|c|c|c|}
\hline \multirow[b]{2}{*}{ Materials } & \multicolumn{3}{|c|}{ Absorbance Ratio } & \multirow{2}{*}{$\begin{array}{c}\text { Ash Level } \\
(\% \mathrm{w} / \mathrm{w})\end{array}$} & \multirow{2}{*}{$\begin{array}{l}\text { Total Acidity } \\
\left(\mathrm{mol} \mathrm{kg}^{-1}\right)\end{array}$} \\
\hline & $\begin{array}{l}\mathrm{A}_{280} / \mathrm{A}_{472} \\
\left(\mathrm{~A}_{2 / 4}\right)\end{array}$ & $\begin{array}{l}\mathrm{A}_{280} / \mathrm{A}_{664} \\
\left(\mathrm{~A}_{2 / 6}\right)\end{array}$ & $\begin{array}{l}\mathrm{A}_{472} / \mathrm{A}_{664} \\
\left(\mathrm{~A}_{4 / 6}\right)\end{array}$ & & \\
\hline HD-HA & 41.94 & 6.28 & 6.68 & 1.20 & 415.30 \\
\hline PS-HA & 34.99 & 5.60 & 6.25 & 0.99 & 565.00 \\
\hline Humic Acid [14] & - & - & $3.0-5.0$ & - & $560.00-890.00$ \\
\hline Fulvic Acid [14] & - & - & $6.0-8.5$ & - & $640.00-1420.00$ \\
\hline
\end{tabular}
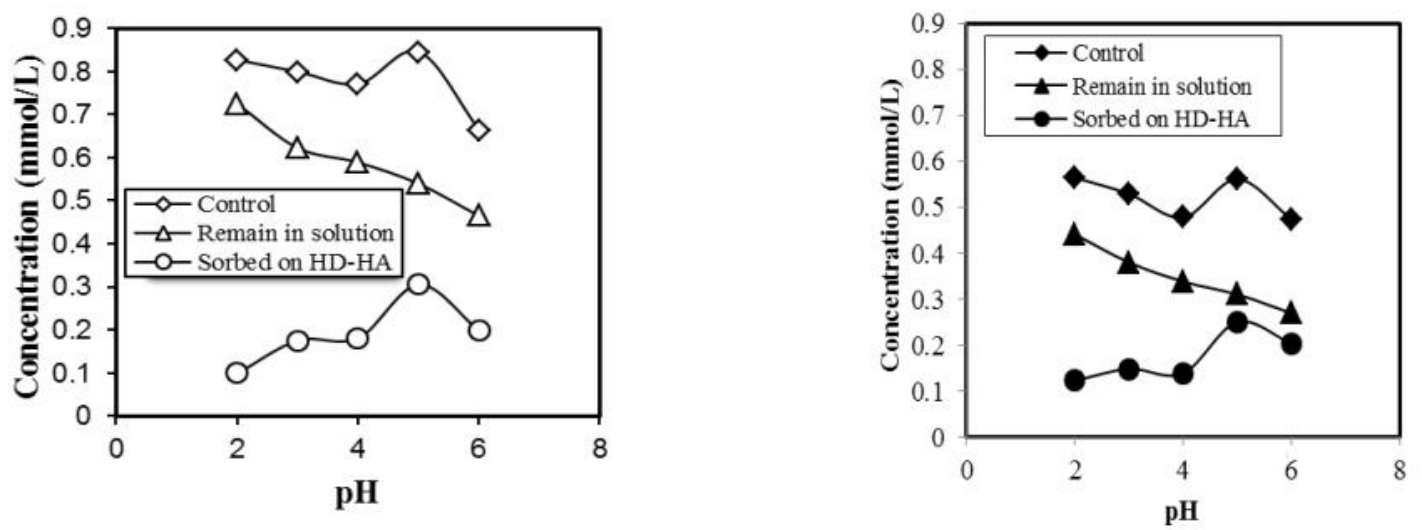

Figure 2. Effect of medium acidity on the distribution of $\mathrm{Zn}(\mathrm{II})$ (left) and $\mathrm{Cd}(\mathrm{II})$ (right) in the presence of HD-HA 
on sorbent. This condition is good for metal ion, but it is poor for HD-HA because it begins to dissolved and to form liquid phase, and it is hard to be separated. Optimum $\mathrm{pH}$ was balance condition between metal ions and HD-HA (sorbent) condition. The optimum $\mathrm{pH}$ of sorption $\mathrm{Zn}$ (II) and $\mathrm{Cd}(\mathrm{II})$ was occurred in $\mathrm{pH} 5$. The optimum $\mathrm{pH} 5$ was also suggested by Rahmawati and Santosa [18] and Burhan [28].

\subsection{Sorption Isotherm}

Determination of capacity and sorption energy of metal ions on HD-HA was plotted using Langmuir and Freundlich isotherm models. Langmuir isotherm model was derived from model described as follow:

$$
\mathrm{A}+\mathrm{S} \underset{k_{d}}{\stackrel{k_{a}}{\rightleftharpoons}} \mathrm{A} * \mathrm{~S}
$$

At time $=0: \quad a=C_{o} \quad b \quad$ Sorbed : $m \quad m \quad m$ In equilibrium: $a-m=C_{e} \quad b-m \quad m$

where $a=C_{o}$ is initial concentration of metal ion $\mathrm{A}(\mathrm{mole} / \mathrm{L}) ; b$ is sorption capacity $(\mathrm{mol} / \mathrm{g}) ; m$ is amount metal ion A sorbed per gram sorbent, $\mathrm{S}$ in equilibrium (mole/g); and $a-m=C_{e}$ is concentration metal ion $\mathrm{A}$ in equilibrium (mole/L). From that model, equilibrium constant, $K$, can be written in Equation (5).

$$
K=\frac{[A * S]}{[A][S]}=\frac{m}{(b-m) C_{e}}
$$

Equation (5) can be rearranging:

$$
m=\frac{K C_{e} b}{1+K C_{e}}
$$

Linear form of Equation (6) was well-known called as Langmuir isotherm [29] model that can be written as:

$$
\frac{C_{e}}{m}=\frac{1}{K b}+\frac{1}{b} C_{e}
$$

Freundlich isotherm [30] form is $m=K_{F} C_{e}{ }^{n}$. This model can be writing as linear form:

$$
\log m=\log K_{F}+1 / n \log C_{e}
$$

where $C_{e}$ is the equilibrium concentration in solution; $b$ is Langmuir's sorption capacity; $K$ represents Langmuir's constant of equilibrium; $m$ is metal sorbed per gram sorbent at equilibrium; $B$ is Freundlich's sorption capacity and, $n$ is constants.
The application of the two models was resulted the sorption parameters shown in Figure 3. The Langmuir isotherm is designed for monolayer sorption of species on a homogeneous surface with the same sorption energy for all active site regardless of the degree of coverage, while the Freundlich is for multilayer sorption on heterogeneous surface with the frequency of sites associated with free energy of sorption decrease exponentially with the increase of free energy. Sorption capacity of $\mathrm{Cd}(\mathrm{II})$ and $\mathrm{Zn}(\mathrm{II})$ was $1.070 \times 10^{-3}$ and $1.329 \times 10^{-3} \mathrm{~mole} / \mathrm{g}$, respectively. Compared with Cd(II), Zn(II) have higher sorption capacity (Table 3). Sorption capacity of $\mathrm{Cd}(\mathrm{II})$ on HD$\mathrm{HA}$ is less compared with another HA from other source as studied by Rahmawati and Santosa (HA from Rawa Pening peat soil, $b=$ $3.83 \times 10^{-3}$ mole/g) [18] and higher than Burhan (HA from dry cow dung powder, $b=8.85 \times 10^{-4}$ mole/g) [28]. This can be explained by two reason, firstly atomic radii for $\mathrm{Cd}(\mathrm{II})$ actually higher than $\mathrm{Zn}$ (II) (1.4 $\AA$ and $1.1 \AA$, respectively), but in hydrate conditions $\mathrm{Zn}$ (II) has higher radii than Cd(II) (6 $\AA$ and $5 \AA$, respectively).

One of the sorbed mechanism metal ions onto functional group in HD-HA is water bridge [27]. This mechanism can be proved from ratio monolayer sorption capacity of $\mathrm{Cd}(\mathrm{II})$ and $\mathrm{Zn}$ (II) closely match with ratio hydrate radii for $\mathrm{Cd}(\mathrm{II})$ and $\mathrm{Zn}(\mathrm{II})$, that was $5: 6$. Secondly, $\mathrm{Zn}$ (II) has stronger acid characteristic than $\mathrm{Cd}$ (II), so that $\mathrm{Zn}$ (II) was more suitable with functional group of HD-HA which has more hard base characteristic. It is proved from comparison between Langmuir monolayer sorption capacity and Freundlich multilayer sorption capacity for $\mathrm{Cd}(\mathrm{II})$ is 19.9 times greater and $\mathrm{Zn}$ (II) is 64.6 times greater. Additionally, $\mathrm{Zn}$ (II) has greater sorption energy than $\mathrm{Cd}(\mathrm{II})$ (Table 4).

Humic acid has many active side as O- (enolate), - $\mathrm{COOH}$ (carboxylic), -NH (amide), -O- (ether), $\mathrm{C}=\mathrm{O}$ (carbonyl), etc. Among the active side, the oxygen containing functional groups such as -O- and - $\mathrm{COO}^{-}$is the most reactive functional groups [27]. FT-IR studies showed that -COO- plays an important role in metal complexation. If we assume -COO- is the responsible group for the adsorption of metal ions, then the capacity (monolayer or monoenergy) Langmuir adsorption may indicate the number of this group. Because metal ions occupy the active site, the strongest interaction occupies first and then the active side with lower energy. Meanwhile, the capacity (multilayer or multi-energy) indicates the Freundlich adsorp- 

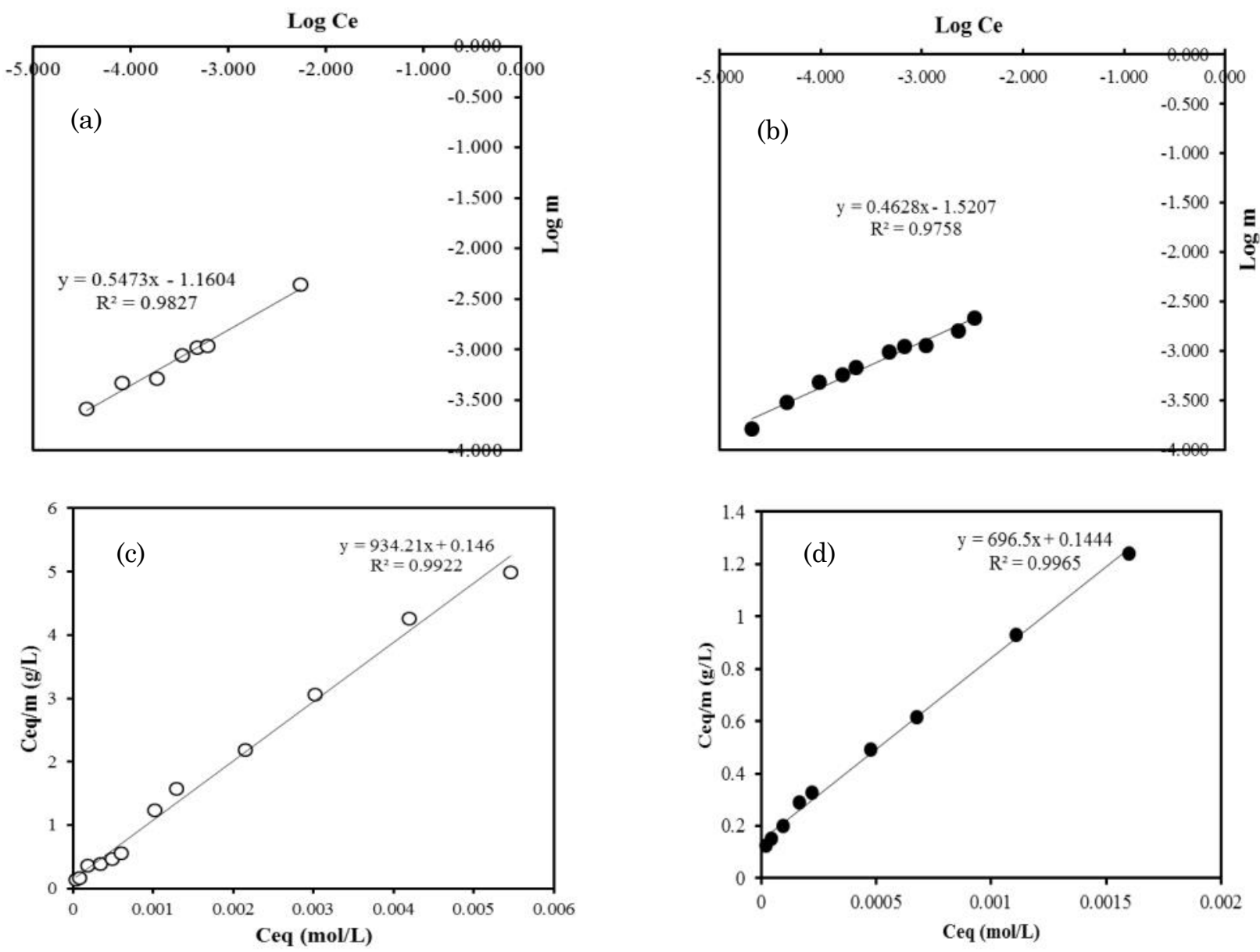

Figure 3. Freundlich isotherm sorption of $\mathrm{Zn}$ (II) (a) and $\mathrm{Cd}(\mathrm{II})$ (c) onto HD-HA and Langmuir isotherm sorption of $\mathrm{Zn}(\mathrm{II})$ (b) and $\mathrm{Cd}(\mathrm{II})$ (d) onto HD-HA

Table 3. Functional group content and total acidity of varied HA

\begin{tabular}{llll}
\hline Materials & $\begin{array}{l}\text { Total Acidity } \\
(\mathrm{cmol} / \mathrm{kg})\end{array}$ & $\begin{array}{l}\text { Carboxylate } \\
(\mathrm{cmol} / \mathrm{kg})\end{array}$ & $\begin{array}{l}-\mathrm{OH} \text { phenolic } \\
(\mathrm{cmol} / \mathrm{kg})\end{array}$ \\
\hline HD-HA (This Work) & 415,3 & 166,3 & 249,0 \\
PS-HA (This Work) & 565,0 & 208,2 & 356,8 \\
Cow Dung-HA [20] & 96,7 & 7,3 & 89,4 \\
PS-HA [7] & 715,8 & 326,6 & 426,2 \\
PS-HA [14] & $560,0-890,0$ & $150,0-570,0$ & $20,0-490,0$ \\
\hline
\end{tabular}

Table 4. Sorption capacity $(b)$, energy $(E)$, and constant of equilibrium $(K)$ obtained from Langmuir isotherm as well as sorption capacity $(B)$ obtained from Freundlich isotherm for the sorption of $\mathrm{Cd}(\mathrm{II})$ onto HD-HA

\begin{tabular}{llllllll}
\hline & \multicolumn{6}{c}{ Sorption parameters } \\
\cline { 2 - 8 } $\begin{array}{l}\text { Metal } \\
\text { ions }\end{array}$ & \begin{tabular}{c}
\multicolumn{7}{c}{ Langmuir } \\
\cline { 2 - 8 }
\end{tabular} & $\mathrm{K}(\mathrm{mol} / \mathrm{L})^{-1}$ & $\begin{array}{l}\mathrm{E}^{\mathrm{a}} \\
(\mathrm{kJ} / \mathrm{mol})\end{array}$ & $\mathrm{R}^{2}$ & $\begin{array}{l}\mathrm{B} \\
\left(10^{-2} \mathrm{~mol} / \mathrm{g}\right)\end{array}$ & $\mathrm{n}$ & $\mathrm{R}^{2}$ \\
\hline $\mathrm{Cd}(\mathrm{II})$ & 1.329 & 5,651 & 21.55 & 0.997 & 2.646 & 2.218 & 0.976 \\
$\mathrm{Zn}(\mathrm{II})$ & 1.070 & 6,399 & 21.86 & 0.992 & 6.912 & 1.827 & 0.983 \\
\hline
\end{tabular}

${ }^{\mathrm{a}} \mathrm{E}=-\mathrm{RT} \ln \mathrm{K}$ 
tion capacity -COO- and all active side together. Interactions were occurred allegedly as electrostatic forces between the metal ions with active sites of HD-HA. FT-IR spectra can provide little information about the electrostatic interaction between sorbate and sorbent (Figure 4). The weakening of the $\mathrm{C}=\mathrm{O}$ absorption of $-\mathrm{COOH}$ on wave number $1720 \mathrm{~cm}^{-1}$ after interaction with $\mathrm{Cd}$ (II) indicates the physical interaction of $\mathrm{C}=\mathrm{O}$ group on the HD-HA acid with $\mathrm{Cd}(\mathrm{II})$.

\subsection{The New Kinetics Equation}

Considering the sorption of metal ions on sorbent is an equilibrium process as illustrated as follow:

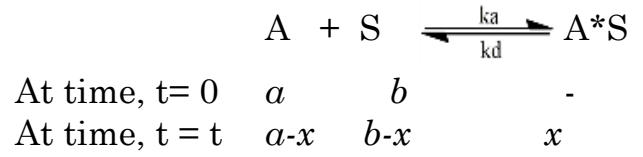

where $A$ is a metal ions; $S$ is an sorbent (HD$\mathrm{HA}) ; k_{a}$ is the sorption rate constant, and $k_{d}$ is desorption rate constant. If $a$ is the initial concentration of metal A $(\mathrm{mol} / \mathrm{L}), b$ is the Langmuir sorption capacity (mol/L) and $x$ is the number of $A$ is adsorbed on the $S(\mathrm{~mol} / \mathrm{L})$, from the same derivation as Langmuir, the equation rate can be written in Equation (9).

$$
r_{a d s}=\frac{d x}{d t}=k_{a}(a-x)(b-x)-k_{d} x
$$

At equilibrium, $d x / d t=0$, so that:

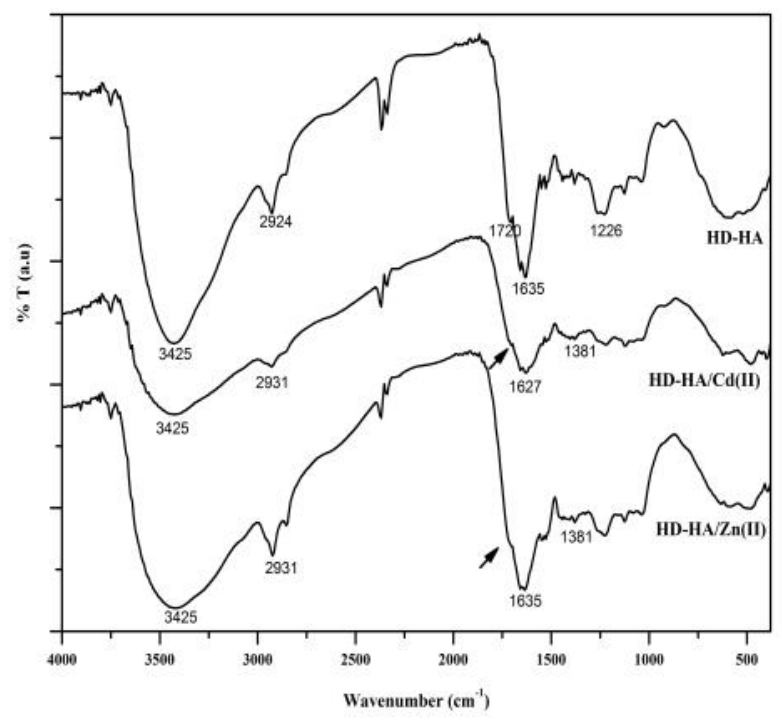

Figure 4. FT-IR spectra of HD-HA before and after interaction with metal ions, $\mathrm{Cd}(\mathrm{II})$ and $\mathrm{Zn}$ (II)

$$
k_{d}=\frac{k_{a}\left(a-x_{e}\right)\left(b-x_{e}\right)}{x_{e}}
$$

Substituting Eq. (9) into Eq. (10) yields:

$$
\frac{d x}{d t}=k_{a}(a-x)(b-x)-\frac{k_{a}}{x_{e}}\left(a-x_{e}\right)\left(b-x_{e}\right)
$$

It can be simplify be a simple form:

$$
\frac{d x}{\left(a b-x_{e} x\right)\left(x_{e}-x\right)}=\frac{k_{a}}{x_{e}} d t
$$

At $t=0$, sorption has not occured yet, so $k_{a}$ is 0 and metal ion of A has not been adsorbed on sorbent $\mathrm{S}$, so $x=0$. Taking integration for the eq. (12) with limit $(a b)$ to $\left(a b-x_{e} x\right), 0$ to $(x)$, and 0 to $t$, so Eq. (12) can be written as:

$\frac{x_{e}}{\left(x_{e}^{2}-a b\right)} \int_{a b}^{a b-x_{e} x} \frac{1}{a b-x_{e} x} d x+\frac{1}{\left(a b-x_{e}^{2}\right)} \int_{0}^{x} \frac{1}{\left(x_{e}-x\right)} d x=\frac{k_{a}}{x_{e}} \int_{0}^{t} d t$

Integration results:

$$
\ln \left(\frac{\left(a b-x_{e} x\right) x_{e}}{\left(x_{e}-x\right) a b}\right)=k_{a} \frac{a b-x_{e}^{2}}{x_{e}} t
$$

Rearranged Eq. (14) gives:

$$
\ln \left(\frac{a b-x_{e} x}{x_{e}-x}\right)=k_{a}\left(\frac{a b-x_{e}^{2}}{x_{e}}\right) t-\ln \left(\frac{x_{e}}{a b}\right)
$$

Or in another form:

$$
\ln \left(x_{e}-x\right)=\ln \left(\frac{x_{e}\left(a b-x_{e} x\right)}{a b}\right)-k_{a}\left(\frac{a b-x_{e}^{2}}{x_{e}}\right) t
$$

The Eq. (16) is surprisingly the same as Lagergren equation, $\ln \left(q_{e}-q_{t}\right)=\ln \left(q_{e}\right)-k_{\text {lag }} t$, where $q_{e}$ and $x_{e}$ has the same unit (mole/L). Thus allegedly linearity of Eq. (16) is similar to the linearity Lagergren pseudo-first order. The same plot between Eq. (16) with a Lagergren pseudofirst-order model is $\ln \left(x_{e}-x\right)$ versus $t$ generates relationships, $k_{\text {lag }}=k_{a}\left(\left(a b-x_{e}{ }^{2}\right) / x_{e}\right)$. If the Eq. (16) gives a straight line, the intercept $\ln \mathrm{q}_{\mathrm{e}}$ from Lagergren has a value equal to $\ln \left(x_{e}(a b\right.$ $\left.\left.x_{e}^{2}\right)\right) / a b$ ) and answered questions Aharoni and Sparks [13] why the parameter $\ln q_{e}$ always have different values with $\ln q_{e}$ obtained from experimental data.

\subsection{Sorption Kinetics}

If Eq. (15) is applied, plot $\ln \left(\left(a b-x_{e} x\right) /\left(x_{e}-x\right)\right)$ vs $t$ generates straight line and the value of $k_{a}$ can be determine from slope. Intercept was $-\ln \left(x_{e} / a b\right)$ and should not be different with 
from calculation $-\ln \left(x_{e} / a b\right)$ from experimental data. The value of $k_{d}$ can be determined from Eq. (10), and if we divide $k_{a}$ with $k_{d}$ yields equilibrium constant, $K$, in which the value of $K$ should not be different from $K$ of isotherm Langmuir. Kinetics profile of sorbed metal ions as function of time can be seen in Figure 5 .

This experiment used $10 \mathrm{mg}$ sorbent and 50 $\mathrm{mL}$ of $\mathrm{Cd}(\mathrm{II})$ and $\mathrm{Zn}(\mathrm{II}) 50 \mathrm{mg} / \mathrm{L}$, so initial concentration of $\mathrm{Cd}(\mathrm{II}), a_{\mathrm{Cd}}=4.355 \times 10^{-4} \mathrm{~mol} / \mathrm{L}(\mathrm{Ar}$ $\mathrm{Cd}=112.4)$ and initial concentration of $\mathrm{Zn}, a_{\mathrm{Zn}}$ $=8.075 \times 10^{-4}$ mole $/ \mathrm{L}(\mathrm{Ar} \mathrm{Zn}=65.4)$. Sorption equilibrium reach after 120 minute interaction, yielded sorption $\mathrm{Cd}(\mathrm{II}), x_{e}(\mathrm{Cd})$ and $\mathrm{Zn}(\mathrm{II}), x_{e}(\mathrm{Zn})$ at equilibrium was $1.353 \times 10^{-4} \mathrm{~mole} / \mathrm{L}$ and $1.865 \times 10^{-4} \mathrm{~mole} / \mathrm{L}$, respectively. Sorption capacity, $b$ of $\mathrm{Zn}(\mathrm{II})$ and $\mathrm{Cd}(\mathrm{II})$ from Langmuir isotherm, is $1.070 \times 10^{-3}$ and $1.329 \times 10^{-3} \mathrm{~mole} / \mathrm{g}$, respectively. If we assume $b$ is a species, it interacts with metal ions $A$ in certain volume, so we can change $b$ into mole/L unit as a, so $b=$ $2.657 \times 10^{-4} \mathrm{~mole} / \mathrm{L}$. Plot data into three kinetics expression, i.e. Lagergren pseudo-first order [2], Ho pseudo-second order [1], and this new kinetics equation [14], can be seen in Table 5 .

In many publications about kinetics equation study, linearity $\left(\mathrm{R}^{2}\right)$ of linear regression is one of the most suitable parameter of any kinetics equation [31-34]. In this work, the best linearity was Ho kinetics equation $\left(\mathrm{R}^{2}\right.$ in $\mathrm{Cd}(\mathrm{II})$ sorption $=0.995 ; \mathrm{Zn}(\mathrm{II})=0.999)$. The most fitted calculation of $x_{e}$ with experimental value of $x_{e}$ was also achieved by Ho kinetics equation. The closeness of experimental value of $x_{\mathrm{e}}$ of
$\mathrm{Cd}(\mathrm{II})$ and $\mathrm{Zn}(\mathrm{II})$ was 1.353 and $1.865 \mathrm{~mole} / \mathrm{L}$, respectively, and calculation value of Ho kinetics equation of $\mathrm{Cd}(\mathrm{II})$ and $\mathrm{Zn}$ (II) was 1.531 and 1.897 mole/L, respectively, as seen in Table 5 . The best linearity $\left(\mathrm{R}^{2}\right)$ and the most fitted $x_{e}$ between experiment and calculation confirmed by Sheela et al. [31]. The Ho kinetics equation was also the most fitted linear regression in the most adsorption system [31-34]. However, explanation about the kinetics equation itself is rarely discussed. One of them, sorption rate constant $\left(k_{a}\right)$ was resulted from Ho and Lagergren kinetics equation. These both value of $k_{a}$, after equated the unit, was always different. This value of $k_{a}$ was independent and can not

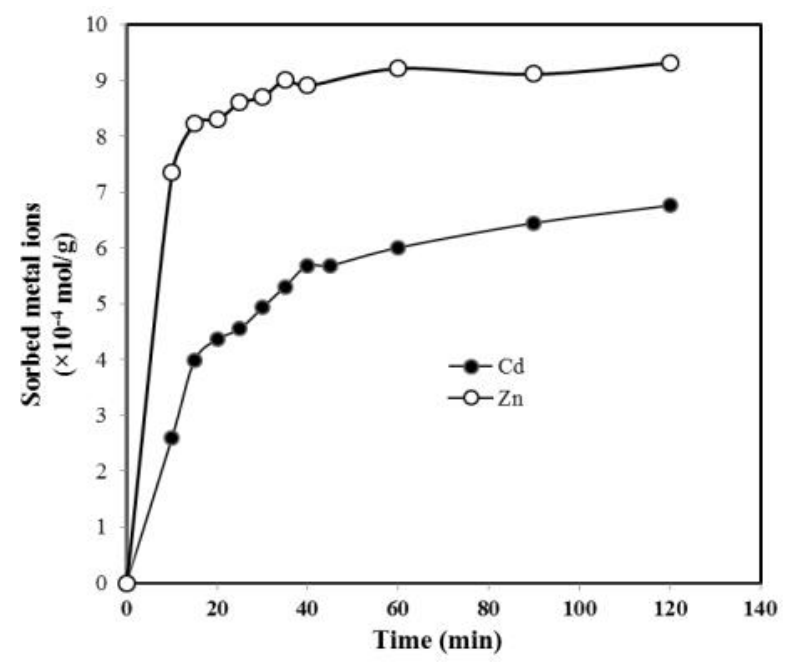

Figure 5. Sorption profile of $\mathrm{Cd}(\mathrm{II})$ and $\mathrm{Zn}(\mathrm{II})$ on HD-HA as a function of interaction time

Table 5. The comparison of linearity and kinetics sorption parameters of $50 \mathrm{~mL}$ metal ions $50 \mathrm{mg} / \mathrm{L}$ onto $10 \mathrm{mg}$ HD-HA in $\mathrm{pH} 5$ at $0-120$ minute

\begin{tabular}{|c|c|c|c|c|c|c|c|c|c|c|c|}
\hline \multirow[t]{2}{*}{$\begin{array}{c}\text { Metal } \\
\text { ions }\end{array}$} & \multirow{2}{*}{$\begin{array}{l}\begin{array}{r}\text { Expe- } \\
\text { riment }\end{array} \\
x_{e} \\
(\mathrm{~mol} / \mathrm{L}) \\
\times 10^{-4}\end{array}$} & \multicolumn{3}{|c|}{$\begin{array}{l}\text { Pseudo-first order } \\
\text { (Lagergren) }\end{array}$} & \multicolumn{3}{|c|}{ Pseudo-second order (Ho) } & \multicolumn{4}{|c|}{ New kinetics equation } \\
\hline & & $\mathrm{R}^{2}$ & $\begin{array}{l}k_{\operatorname{lag}} \\
\left(\min ^{-1}\right) \\
\times 10^{-2}\end{array}$ & $\begin{array}{l}x_{e} \\
(\mathrm{~mol} / \mathrm{L}) \\
\times 10^{-5}\end{array}$ & $\mathrm{R}^{2}$ & $\begin{array}{l}k_{H o} \\
\left(\mathrm{~min}^{-1}\right. \\
\left.(\mathrm{mol} / \mathrm{L})^{-1}\right) \\
\times 10^{3}\end{array}$ & $\begin{array}{l}x_{e} \\
(\mathrm{~mol} / \mathrm{L}) \\
\times 10^{-4}\end{array}$ & $\mathrm{R}^{2}$ & $\begin{array}{l}k_{a} \\
\left(\min ^{-1}\right. \\
\left.(\mathrm{mol} / \mathrm{L})^{-1}\right)\end{array}$ & $\begin{array}{l}k_{d} \\
\left(\min ^{-1}\right) \\
\times 10^{-2}\end{array}$ & $\begin{array}{l}x_{e} \\
(\mathrm{~mol} / \mathrm{L}) \\
\times 10^{-4}\end{array}$ \\
\hline $\mathrm{Cd}(\mathrm{II})$ & 1.353 & 0.976 & 3.07 & 9.137 & 0.995 & 5.217 & 1.531 & 0.982 & 43.178 & 1.250 & 1.094 \\
\hline Zn(II) & 1.865 & 0.961 & 5.62 & 6.00 & 0.999 & 2.179 & 1.897 & 0.980 & 73.215 & 6.718 & 0.726 \\
\hline
\end{tabular}

Table 6. Comparison parameters between manually calculation and linear regression of new kinetics equation

\begin{tabular}{|c|c|c|c|c|c|c|c|c|}
\hline \multirow[t]{2}{*}{$\begin{array}{l}\text { Metal } \\
\text { ions }\end{array}$} & \multicolumn{2}{|c|}{$\begin{array}{l}-\ln \left(x_{e} / a b\right) \text { of new } \\
\text { kinetics equation }\end{array}$} & \multicolumn{2}{|c|}{$k_{a} / k_{d}=K$} & \multicolumn{2}{|c|}{$\begin{array}{l}\text { Intercept of plot } \\
\ln \left(x_{e}-x\right) \text { vs } t\end{array}$} & \multicolumn{2}{|c|}{$k_{\text {lag }}$ and $k_{a}$} \\
\hline & $\begin{array}{l}\text { Calcu- } \\
\text { lation }\end{array}$ & $\begin{array}{l}\text { Intercept } \\
\text { from } \\
\text { regres- } \\
\text { sion }\end{array}$ & $\begin{array}{l}k_{a} / k_{d}=K \\
\text { from regres- } \\
\text { sion } \\
(\mathrm{mol} / \mathrm{L})^{-1}\end{array}$ & $\begin{array}{l}\mathrm{K} \text { from } \\
\text { Lang- } \\
\text { muir eq. } \\
(\mathrm{mol} / \mathrm{L})^{-1}\end{array}$ & $\begin{array}{l}\ln q_{e} \text { of } \\
\text { Lagergren } \\
\text { equation }\end{array}$ & $\begin{array}{l}\text { Calculation } \\
\ln \left(x_{e}(a b-\right. \\
\left.\left.\left.x_{e}^{2}\right)\right) / a b\right)\end{array}$ & $\begin{array}{l}k_{\text {lag }} \text { from } \\
\text { Lager- } \\
\text { gren eq. } \\
\left(\min ^{-1}\right)\end{array}$ & $\begin{array}{l}k_{\text {lag }} \text { from } k_{\text {lag }}=k_{a} \\
\left.\left(a b-x_{e}^{2}\right) / x_{e}\right) \\
\left(\min ^{-1}\right)\end{array}$ \\
\hline $\mathrm{Cd}(\mathrm{II})$ & 7.0638 & 6.8517 & 3,452 & 5,651 & -9.3005 & -9.0807 & 0.0307 & 0.0311 \\
\hline $\mathrm{Zn}(\mathrm{II})$ & 6.9838 & 6.0408 & 10,898 & 6,399 & -9.7206 & -6.984 & 0.0561 & 0.0562 \\
\hline
\end{tabular}


be compared with another parameter. There is no scale to say that the parameter $\left(k_{a}\right)$ was really correct. The correlation parameters for the Lagergren and Ho kinetics equation were low and the calculated $x_{e}$ values obtained from the Lagergren kinetic equations are not reasonable values [32]. In this work, beside the parameters of new kinetics equations has good correlation to Langmuir data, the parameters can also be compared among calculation and experimental data (Table 6).

Application of Eq. (15) as the new kinetics equation on sorption data of $\mathrm{Cd}(\mathrm{II})$ and $\mathrm{Zn}$ (II) onto HD-HA results good linearity between ln $\left(\left(a b-x_{e} x\right) /\left(x_{e}-x\right)\right)$ vs $t$, which $\mathrm{R}^{2}$ higher than Lagergren pseudo-first order expression (Figure 6). Best linearity obtained by Ho pseudo-second order expression which $\mathrm{R}^{2}=0.999$ for $\mathrm{Zn}$ (II) and 0.995 for $\mathrm{Cd}(\mathrm{II})$. This evidence proves that Ho kinetics expression has suitable condition of experiment comparison between initial concentration of metal ions $(a)$ and sorption capacity $(b)$ which is approximately $2: 3$ for $\mathrm{Cd}(\mathrm{II})$ and 1:4 for $\mathrm{Zn}(\mathrm{II})$. However, both Ho and Lagergren have not good relationship with data from Langmuir sorption isotherm. Sorption rate constant, $k_{a}$, resulted from slope in Eq. (15), was $73.215\left(\mathrm{~min}^{-1}(\mathrm{~mole} / \mathrm{L})^{-1}\right)$ for $\mathrm{Zn}(\mathrm{II})$ and

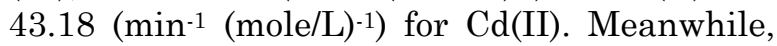
desorption rate constant, $k_{d}$, resulted from Eq. (10) was $6.718 \times 10^{-3} \mathrm{~min}^{-1}$ for $\mathrm{Zn}(\mathrm{II})$ and $1.250 \times 10^{-2} \mathrm{~min}^{-1}$ for $\mathrm{Cd}(\mathrm{II})$. If we divide $k_{a}$ with $k_{d}$ from this new kinetics equation yields equilibrium constant, $K$, which was $3,452(\mathrm{~mole} / \mathrm{L})^{-1}$ for $\mathrm{Cd}(\mathrm{II})$ and 10,898 (mole/L) ${ }^{-1}$ for $\mathrm{Zn}(\mathrm{II})$. From Langmuir data, it was observed that sorption equilibrium constant, $K_{L} \mathrm{Cd}(\mathrm{II})$ and $\mathrm{Zn}(\mathrm{II})$ was 5,651 and 6,399 (mole/L) ${ }^{-1}$ ), respectively. The comparison value between $K$ from new kinetics equation and $K_{L}$ from Langmuir data shows that sorption $\mathrm{Cd}(\mathrm{II})$ has closer value $(3,452$ $(\mathrm{mole} / \mathrm{L})^{-1}$ to $5,651{\left.(\mathrm{~mole} / \mathrm{L})^{-1}\right)}$ than sorption $\mathrm{Zn}$ (II) $\left(10,898\right.$ (mole/L) $^{-1}$ to 6,399 (mole/L) $\left.^{-1}\right)$. This evidence proves that the parameter of new kinetic equation can be confirmed with Langmuir isotherm data.

The value of equilibrium constant in both $K$ from new kinetics equation and $K_{L}$ from Langmuir isotherm should be equal. From our previous work, the differences of this value $K$ and $K_{L}$ generates from ratio of initial concentration of sorbate (a) and sorption capacity (b) [14]. Because the $k_{a}, k_{d}$, and $x_{e}$ are the function of $a$ and $b$ [14]. It might be the correct that ratio of $a$ and $b$ generates the equal $K$ and $K_{L}$. Additionally, every sorbent and sorbate has the own this ration for equality of $K$ and $K_{L}$.
The values of $k_{a}, k_{d}$, and $x_{e}$ from new kinetics equation can be seen in Table 4 . The value of $k_{a}, k_{d}, K$, and $E$ of $\mathrm{Zn}(\mathrm{II})$ was higher than $k_{a}, k_{d}, K$, and $E$ of $\mathrm{Cd}(\mathrm{II})$. The higher value of $k_{a}, k_{d}$, and $K$ was caused by suitability hard-hard characteristic between $\mathrm{Zn}$ (II) and functional group of HD-HA. The higher value of $k_{a}$ and $k_{d}$ means that $\mathrm{Zn}(\mathrm{II})$ sorbed faster than $\mathrm{Cd}(\mathrm{II})$, but $\mathrm{Zn}(\mathrm{II})$ also desorbed greater then $\mathrm{Cd}(\mathrm{II})$. It was proved that in $60^{\text {th }}$ minutes, $\mathrm{Zn}$ (II) has reached the equilibrium, but $\mathrm{Cd}(\mathrm{II})$ sorption still increases till more $120^{\text {th }}$ minute (Figure 5). The suitability of hard-hard characteristic between $\mathrm{Zn}$ (II) and functional group of HD-HA lead the faster sorption, but the bigger hydrate radii of $\mathrm{Zn}$ (II) $(6 \AA)$ than $\mathrm{Cd}(\mathrm{II})(5 \AA)$ cause the sorption capacity of $\mathrm{Cd}(\mathrm{II})$ higher than $\mathrm{Zn}$ (II) (Table 4). Smaller hydrate radii of $\mathrm{Cd}(\mathrm{II})$ than $\mathrm{Zn}$ (II) leads to higher amount of sorbed Cd(II).

Aharoni and Sparks [13] stated that intercept from Lagergren linear regression, $\ln q_{e}$ always have different values with calculated ln $q_{e}$ obtained from experimental data. In the same unit (mole $\mathrm{L}^{-1}$ ) of eq. (16) and Lagergren kinetics equation we can conclude that $\ln q_{e}$ of Lagergen kinetics equation is a more complex function of initial metal ion concentration $(a)$, sorption capacity $(b)$, and sorbed metal ion at equilibrium $\left(x_{e}\right)$. The evidence of this statement was calculation of $\left.\ln \left(x_{e}\left(a b-x_{e}^{2}\right)\right) / a b\right)$ give nearly close value with $\ln q_{e}$ from Lagergren equation (Table 6). Eq. (16) proves that $k_{\text {lag }}$ was a complex function from $k_{a}\left(\left(a b-x_{e}^{2}\right) / x_{e}\right)$. This result answered question by Aharoni and Spark [13], that intercept should have similar value between calculation and regression. These results proves that the new kinetics equation has more advantages in determining sorption rate constant, $k_{a}$, desorption rate constant, $k_{d}$, and equilibrium constant, $K$, from single set data comparing both Lagergren and Ho kinetics expression. This new kinetics equation also has good relation between parameters resulted from manually calculation and linear regression, which was not owned by other kinetics equation.

\section{Conclusions}

It was obviously observed from physical appearance, total acidity, UV-Vis, and FT-IR study that horse dung can be source of humic acid. It was proved that this new kinetics equation have good relation between parameters resulted from manually calculation and linear regression, which is not seen on other sorption kinetics equation. The new kinetics equation 
was successfully applied to determine the value of intercept of the well-known Lagergren equation which has nearly close value with calculation of $\ln \left(\left(x_{e}\left(a b-x_{e}^{2}\right)\right) / a b\right)$, the value of equilibrium constant, $K=k_{a} / k_{d}$ from proposed kinetics expression which fairly close with equilibrium constant from Langmuir isotherm model $\left(K_{L}\right)$, and intercept of this new kinetics equation $\left(-\ln \left(x_{e} / a b\right)\right)$ was nearly close with $-\ln \left(x_{e} / a b\right)$ from the calculation. Additionally, this new kinetics equation has more advantages in deter-
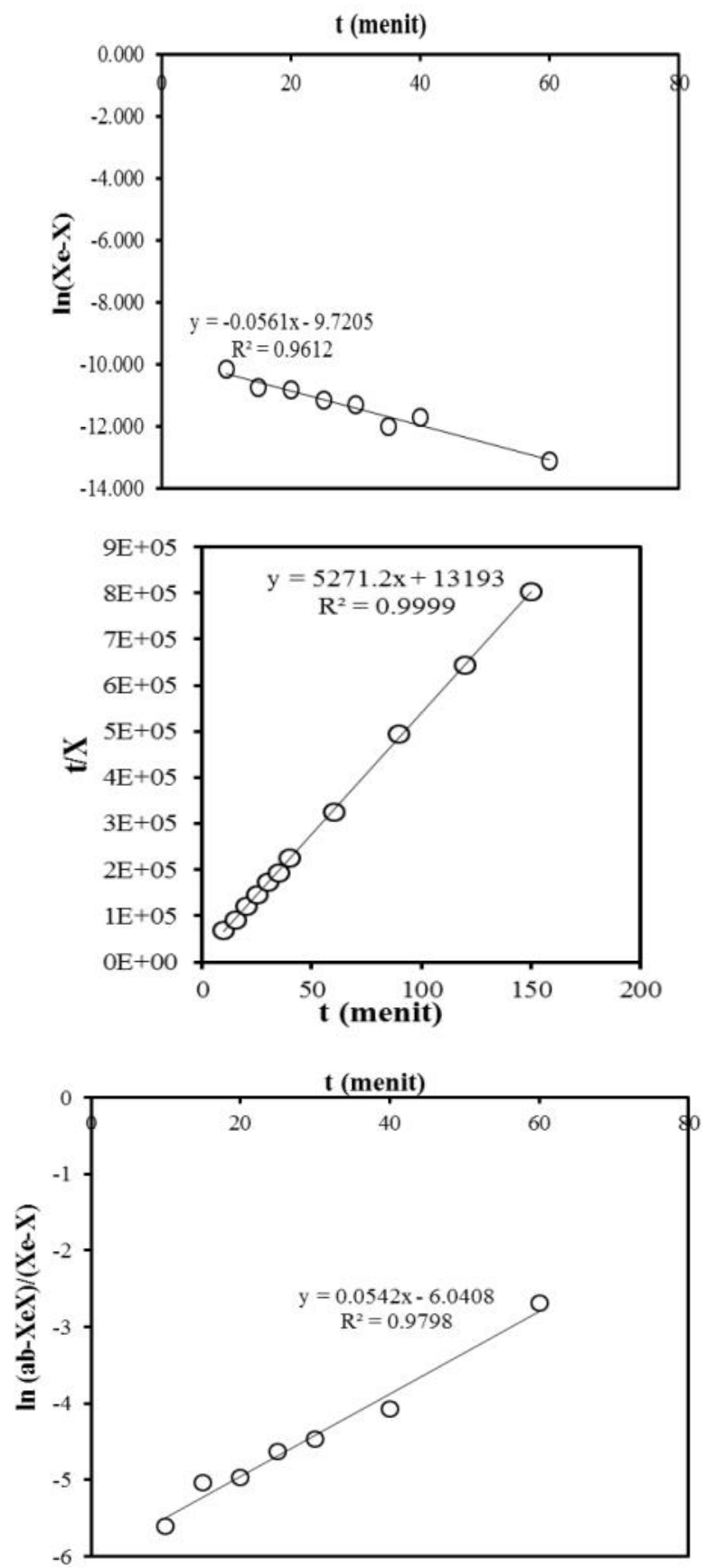

mining sorption parameters, i.e. $k_{a}, k_{d}$, and $K$ from single set data comparing both Lagergren and Ho kinetics expression.

\section{Acknowledgments}

We thank to Ministry of Research, Technology and Higher Education, The Republic of Indonesia through Graduated Scholarship for Domestic Education (BPP-DN) contract number 1414.59/E4.4/2013 for finance this work.
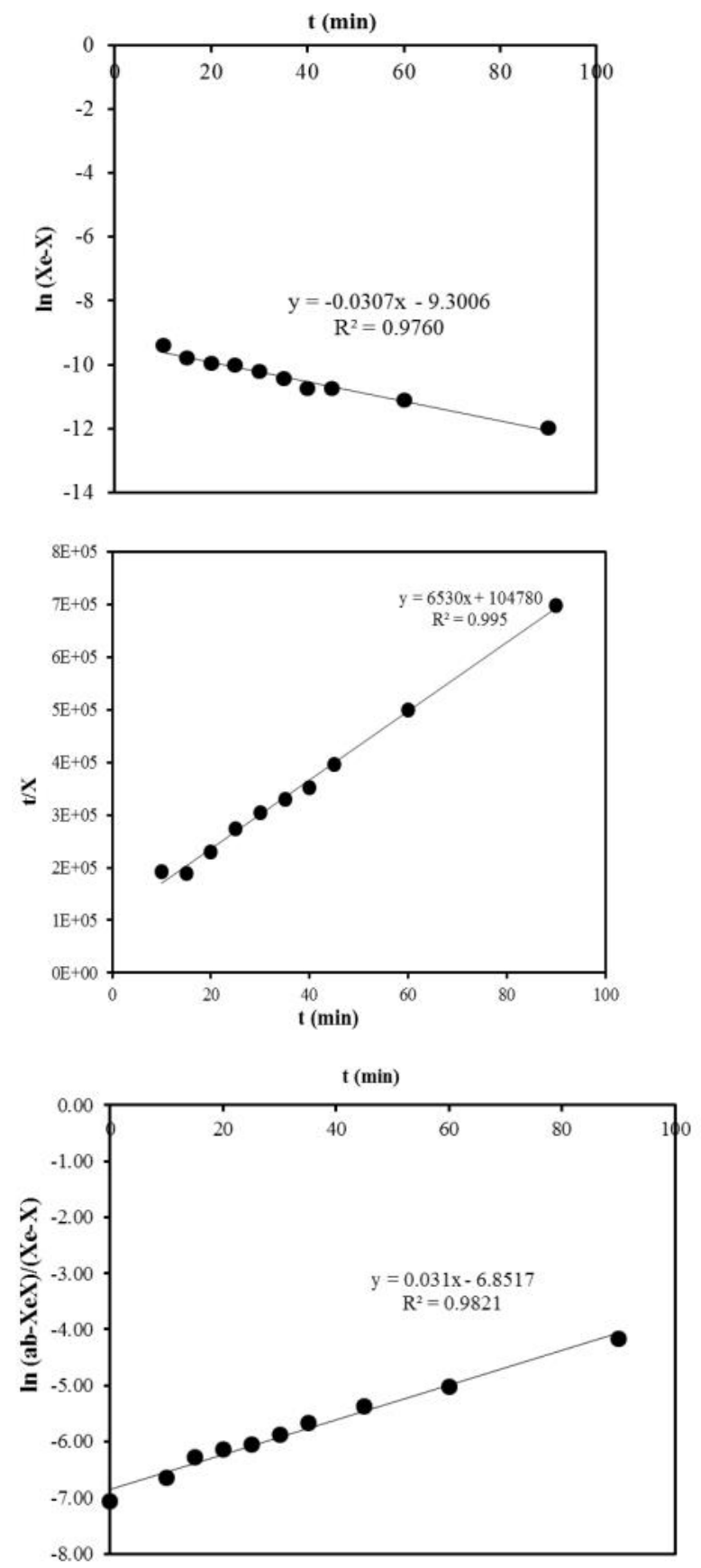

Figure 6. Linearity from regression of pseudo-first order Lagergren, pseudo-second Ho, and the kinetics equation of $\mathrm{Zn}$ (II) (left-from above to down, respectively) and $\mathrm{Cd}(\mathrm{II})$ (right-from above to down, respectively) onto HD-HA 


\section{References}

[1] Ho, Y.S. (2006). Review Second-order Model for Adsorption Systems. Journal of Hazardous Materials, B136: 681-689.

[2] Lagergren, S. (1898). About the Theory of Socalled Adsorption of Soluble Substance, Kungliga Svenska Vetenskapsakademies, Handlingar. Band, 24(4): 1-39.

[3] Agarwal, A.K., Kadu, M.S., Pandhurnekar, C.P., Muthreja, I.L., (2015). Kinetics Study on the Adsorption of $\mathrm{Ni}^{2+}$ Ions onto Fly Ash. Journal of Chemical Technology and Metallurgy, 50 (5): 601-605

[4] Ho, Y., McKay, G. (1999). Pseudo Second Order Model for Sorption Process. Process Biochem. 34: 451-465.

[5] Chien, S.H., Clayton, W.R., (1980). Application of Elovich Equation to the Kinetics of Phosphate Release and Sorption in Soils. Soil Science Society of America, 44: 265-268.

[6] Wu, F.C., Tseng, R.L., Juang, R.S. (2009). Characteristic of Elovich Equation Used for the Analysis of Adsorption Kinetics in Dyechitosan Systems. Chemical Engineering Journal, 150: 366-373.

[7] Ritchie, A.G. (1977). Alternative to the Elovich Equation for the Kinetics of Adsorption of Gases on Solids. Journal of the Chemical Society, Faraday Transactions 1. 73: 16501653.

[8] Sobkowsk, J., Czerwinski, A. (1974). Kinetics of Carbon Dioxide Adsorption on a Platinum Electrode. Journal of Electroanalytical Chemistry, 55: 391-397.

[9] Blanchard, G., Maunaye, M., Martin, G. (1984). Removal of Heavy-metals from Waters by Means of Natural Zeolites. Water Research, 18: 1501-1507.

[10] Biskup, B., Subotic, B. (2004). Kinetic Analysis of the Exchange Processes between Sodium Ions from Zeolite A and Cadmium, Copper and Nickel Ions from Solutions. Separation and Purification Technology, 37: 17-31.

[11] Ho, Y.S., Ng, J.C.Y., McKay, G. (2000). Kinetics Pollutant Sorption by Biosorbent: Reviews. Separation \& Purification Reviews, 29(2): 189-232.

[12] Ho, Y.S., McKay, G., Wase, D.A.J., Forster, C.F. (2000). Study of the Sorption of Divalent Metal Ions on to Peat. Adsorption Science and Technology, 18(7): 639-650.

[13] Aharoni, C., Sparks, D.L., (1991). Kinetics of Soil Chemical Reaction - A Theoretical Treatment, in Rates of Soil Chemical Processes, edited by Sparks, D.L., Suarez, D.L., pp.1-18, Madison, WI: Soil Science Society of America.
[14] Rusdiarso, B., Basuki, R., Santosa, S.J., (2016). Evaluation of Lagergren Kinetics Expression of Sorption of $\mathrm{Zn}^{2+}$ onto Horse Dung Humic Acid (HD-HA). Indonesian Journal of Chemistry, 16(3): 338-346.

[15] Aiken, G.R., Mcknight, D.M., Wershaw, R.L. (1985). Humic Substance in Soil, Sediment, and Water. New York: John Willey \& Sons.

[16] Santosa, S.J., Siswanta, D., Kurniawan, A., Rahmanto, W.H. (2007). Hybrid of Chitin and Humic Acid as High Performance Sorbent for Ni(II). Surface Science, 601: 5155-5161

[17] Santosa, S.J., Siswanta, D., Sudiono, S., Utariningrum, R. (2008). Chitin-humic Acid Hybrid as Adsorbent for $\mathrm{Cr}$ (III) in Effluent of Tannery Wastewater Treatment. Applied Surface Science, 254: 7846-7850.

[18] Rahmawati, A., Santosa, S.J. (2013). Adsorption Study of $\mathrm{Pb}(\mathrm{II})$ and $\mathrm{Cd}(\mathrm{II})$ Metals on $\mathrm{Hu}-$ mic Acid in Aqueous Medium. Alchemy, 2(1), 46-57

[19] Samat, Lesbani, A. (2012). Interaction Study of Zinc(II) on Muara Kuang's Humic Acid and Its Application for Zinc Platting Industry Wastewater. Jurnal Penelitian Sains, 15 (1): $22-25$

[20] Santosa, S.J., (2014). Sorption Kinetics of Cd(II) Species on Humic Acid-Based Sorbent. CLEAN Soil Air Water, 42 (6): 760-766.

[21] Hooijer, A., Silvius, M., Wösten, H., Page, S. (2006). Peat- $\mathrm{CO}_{2}$, Assessment of $\mathrm{CO}_{2}$ Emission from Drained Peat land in South East Asia, Delft Hydraulics Report Q3943, Delft Institute of Technology.

[22] Antaressa, A. (2011). Management of Horse (Equus caballus) Dung in Nusantara Polo Club (NPC), Karanggan, Bogor, Bachelor Thesis, Department of Production and Veterinary Technology, Bogor Agricultural Institute.

[23] Stevenson, F.J., (1994). Humus Chemistry: Genesis, Composition, Reaction. Second Edition. New York: John Wiley \& Sons.

[24] Agarwal, S.P., Anwer, M.D.K., Khanna, R., Ali, A., Sultana, Y. (2011). Humic Acid from Shilajit-A Psycho-Chemical and Spectroscopic Characterization. Journal Serbian Chemical Society, 75(3): 413-422.

[25] Albrecht, R., Le Petit, J., Terrom, G., Périssol, C. (2011). Comparison between UV Spectroscopy and NIRS to Assess Humification Process during Sewage Sludge and Green Wastes Co-composting. Bioresource Technology, 102(6): 4495-4500.

[26] Barot, N.S., Bagla, H.K. (2009). Extraction Humic Acid from Biological Matrix - Dry Cow 
Dung Powder. Green Chemistry Letters and Reviews, 2(4): 217-221.

[27] Sudiono, S., Yuniarti, M., Siswanta, D., Kunarti, E.S., Triyono, Santosa, S.J. (2017). The Role of Carboxyl and Hydroxyl Group of Humic Acid in Removing $\mathrm{AuCl}_{4}$ from Aqueous Solution. Indonesian Journal of Chemistry, 17(1): 95-104.

[28] Burhan, A.H. (2014). Adsorption Study of Competitive Cadmium(II) and Zinc(II) onto Green Adsorbent-Cow Dung Humic Acid, Master Thesis, Department of Chemistry, Universitas Gadjah Mada.

[29] Freundlich, H. (1906). Adsorption in Solution. Physical Chemistry, 57: 384-410.

[30] Langmuir, I. (1918). Adsorption Gases on Plane Surface of Glass, Mica, and Platinum. Journal of American Chemical Society, 40: 1361-1403.
[31] Sheela, T., Nayaka, Y.A., Viswanatha, R., Basavanna, S., Venkatesha, T.G. (2012). Kinetics and Thermodynamics Studies on the Adsorption of $\mathrm{Zn}(\mathrm{II}), \mathrm{Cd}(\mathrm{II})$ and $\mathrm{Hg}$ (II) from Aqueous Solution using Zinc Oxide Nanoparticles. Powder Technology, 217: 163-170.

[32] Wang, C., Liu, J., Zhang, Z., Wang, B., Sun, H. (2012). Adsorption of $\mathrm{Cd}(\mathrm{II}), \mathrm{Ni}(\mathrm{II})$, and $\mathrm{Zn}$ (II) by Tourmaline at Acidic Conditions: Kinetics, Thermodynamics, and Mechanisms. Industrial \& Engineering Chemistry Research, 51: 4397-4406.

[33] Semerjian, L. (2010). Equilibrium and Kinetics of Cadmium Adsorption from Aqueous Solutions using Untreated Pinus halepensis sawdust. Journal of Hazardous Material, 173: 236-242.

[34] Li, Y., Yue, Q., Gao, B. (2010). Adsorption Kinetics and Desorption of $\mathrm{Cu}(\mathrm{II})$ and $\mathrm{Zn}$ (II) from Aqueous Solution onto Humic Acid. Journal of Hazardous Material, 178: 455-461. 